\title{
Characteristic activity and migration of episodic tremor and slow-slip events in central Japan
}

\author{
Kazushige Obara and Shutaro Sekine \\ National Research Institute for Earth Science and Disaster Prevention, \\ Tsukuba, Ibaraki 305-0006, Japan
}

(Received June 27, 2008; Revised December 24, 2008; Accepted January 27, 2009; Online published August 31, 2009)

\begin{abstract}
Continuous seismic data and tilt measurements in the Aichi and Mie regions of central Japan indicate significant migration of episodic non-volcanic deep tremors and short-term slow-slip events on the subducting plate interface at the deeper extension of the mega-thrust earthquake seismogenic zone. These episodic tremor and slip (ETS) events occur in two concentrated regions on either side of Ise Bay at recurrence intervals of approximately every 6 months throughout 2004 and 2005, separated by a distinct tremor gap. A migrating tremor episode from the southern edge of the Mie region in January 2006, however, is found to have crossed aseismic Ise Bay along a continuous $200 \mathrm{~km}$ long strike of the subducting Philippine Sea Plate. Coincident with the migration of tremors, very low frequency earthquakes with a predominant frequency of $0.05 \mathrm{~Hz}$ and tilt changes lasting for a few days were detected. Inversion analysis of the tilt data indicates that at least five reverse faultings with an average slip length of $1 \mathrm{~cm}$ took place on the plate boundary, migrating from southwest to northeast, equivalent to a total moment release of $M_{\mathrm{w}}$ 6.2. The tremor seismicity gap at Ise Bay is attributed to the presence of a small ridge in the Philippine Sea Plate that blocks most propagating ETS events. The 2006 episode propagated orthogonal to the majority of ETS event in this region, and was found not to be obstructed by the ridge structure.
\end{abstract}

Key words: Non-volcanic tremor, slow-slip event, subduction zone, plate interface, transition zone, migration.

\section{Introduction}

Non-volcanic deep tremors and accompanying transient slow-slip events, which are termed episodic tremor and slip (ETS) have recently been discovered as a new geophysical phenomenon in the transition zone (Hyndman et al., 1997) at a subducting plate interface. Such ETS events have been detected in southwest Japan (Obara, 2002; Obara et al., 2004; Hirose and Obara, 2005, 2006; Obara and Hirose, 2006) and at the Cascadia margin in North America (Dragert et al., 2001, 2004; Miller et al., 2002; Rogers and Dragert, 2003; Szeliga et al., 2004; Melbourne et al., 2005), and are considered to be the product of stress accumulation and relaxation in the subduction system in a similar manner to mega-thrust earthquakes. In southwest Japan, the Philippine Sea Plate subducts from the Nankai Trough, and mega-thrust earthquakes occur in this region at recurrence intervals of approximately 100 years (Ando, 1975). Non-volcanic deep tremors (Obara, 2002) are distributed along a narrow belt parallel to the deep limit of the slip distribution of past major earthquakes (Sagiya and Thatcher, 1999). Short-term slow-slip events associated with active tremors have been found to recur at intervals of approximately 6 months in some regions of the tremor belt zone (Obara et al., 2004; Obara and Hirose, 2006). Such coupling between tremors and short-term slow-slip events is usually characterized by source migration. In western

Copyright (c) The Society of Geomagnetism and Earth, Planetary and Space Sciences (SGEPSS); The Seismological Society of Japan; The Volcanological Society of Japan; The Geodetic Society of Japan; The Japanese Society for Planetary Sciences; TERRAPUB
Shikoku, for example, tremor epicenters have been found to migrate along the strike of the Philippine Sea Plate at a speed of close to $10 \mathrm{~km} /$ day (Obara, 2002) and the location of the source fault of the corresponding slow-slip event has been roughly estimated to move with the tremor activity (Obara et al., 2004). The extent of such ETS events in the period from 2001 to 2004 in western Shikoku was limited to within $100 \mathrm{~km}$ (Obara and Hirose, 2006).

On the Cascadia margin, ETS events have been found to persist for up to 7 weeks, migrating along strike for over $300 \mathrm{~km}$. The interval of ETS recurrence in Cascadia is approximately 11 months in the southern (Szeliga et al., 2004) and 14-16 months in the northern (Miller et al., 2002). The transient slip events in Cascadia have been detected by continuous global positioning system (GPS) monitoring. Similar ETS events in southwest Japan have not been recognized by GPS, but been detected by continuous tilt monitoring.

In the Mie region (northeastern part of Kii Peninsula), on the western side of Ise Bay, the ETS events were found to recur approximately every 6 months in the period from 2001 to 2004 (Obara and Hirose, 2006). Recently, in the Aichi region on the eastern side of Ise Bay, slow-slip events have been recorded in association with the tremor peak (Hirose and Obara, 2006). Although the past ETS activity, on either side of the bay has been found to occur at similar times, no tremors have been detected in the immediate vicinity of Ise Bay. In the present study, the continuous migration of an ETS event across the tremor seismicity gap of Ise Bay is reported for the first time. This event occurred in January 2006 and lasted for more than 2 weeks, propagating 
gradually along the strike of the Philippine Sea Plate from the Mie region into the Aichi region.

\section{Deep, Low-frequency Tremors}

The Japanese National Research Institute for Earth Science and Disaster Prevention (NIED) operates a network of three-component, short-period, high-sensitivity seismographs known as Hi-net (Okada et al., 2004; Obara et al., 2005). Hi-net stations are distributed throughout Japan at intervals of $20-30 \mathrm{~km}$. Data are acquired continuously at these stations at a sampling frequency of $100 \mathrm{~Hz}$. Due to the emergent nature of the recorded signals, tremors are difficult to identify from raw seismograms. However, owing to similarities between neighboring stations, tremors can be well recognized by aligning the envelopes of bandpassfiltered seismograms with a pass band of $2-16 \mathrm{~Hz}$. The hypocenters of tremors are then estimated from the continuous Hi-net data by an envelope cross-correlation method (Obara, 2002; Obara and Hirose, 2006).

Figure 1 shows the distribution of tremor epicenters in central Japan. The tremors occur at depths of approximately $30 \mathrm{~km}$, tracing a narrow belt along the strike of the subducting Philippine Sea Plate. The epicentral distribution of tremors corresponds to a depth contour of $35-40 \mathrm{~km}$ of the oceanic Moho discontinuity determined by receiver function analysis (Shiomi et al., 2008). The source location of the tremors is therefore inferred to coincide roughly with the plate interface, $5-10 \mathrm{~km}$ above the oceanic Moho dis-

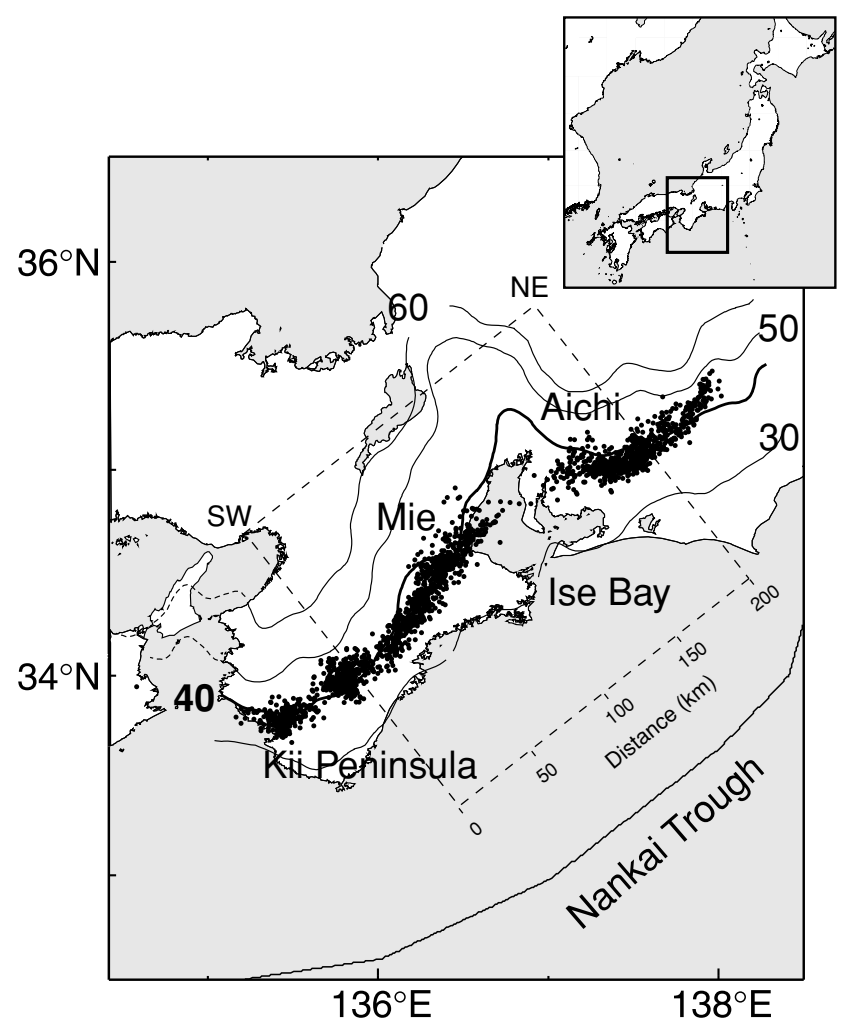

Fig. 1. Distribution of tremor epicenters in central Japan. Points denote centers of distributed tremors at 1 hour intervals from 2001 to 2003. Solid lines denote depth contours $(\mathrm{km})$ of the oceanic Moho discontinuity in the subducting Philippine Sea Plate as estimated by receiver function analysis (Shiomi et al., 2008). Dashed square denotes the region targeted in Fig. 2. continuity.

A distinct gap in the distribution of tremor epicenters can be seen in the vicinity of Ise Bay, dividing the tremor activity into east and west regions corresponding to Aichi and Mie, respectively. This seismic gap is considered as a boundary separating two segments. Figure 2 plots the tremor activity from 2003 to 2006 for these two regions. In the Mie region west of Ise Bay, major tremor activity recurred at an interval of approximately 6 months, migrating from Ise Bay to the southwest over this period. The active tremor episode recorded in January 2006 occurred at the expected timing, but differs from the other events in length of the tremor source and the direction of migration.

The tremor activity in the Mie and Aichi regions in January 2006 is shown in Fig. 3. Minor activity with small amplitudes began in the southern part of the Mie region on January 5. From January 8, tremors with large amplitudes became frequent, and the epicenters migrated gradually north-northeastward, crossing Ise Bay, and continuing east-northeastward in the Aichi region at a speed of approximately $10 \mathrm{~km} /$ day. This is the first record of tremor activity crossing Ise Bay. This event had the longest tremor source distribution on record, extending for a length of approximately $200 \mathrm{~km}$ along the strike of the subducting Philippine Sea Plate. Recently, Ito et al. (2007) detected very low frequency (VLF) earthquakes with a predominant frequency of $0.05 \mathrm{~Hz}$ in this region, as indicated in Fig. 3. The tremors and VLF events appear to be concentrated spatiotemporally in at least five groups, suggesting a genetic relationship between these events.

Figure 4 shows the epicentral distribution of tremors and VLF earthquakes at 2 day intervals in the period of January 4-23, 2006. Distinct migration from southwest to northeast can be recognized from these distributions. This migration pattern differs from that for the other major episodes in the Mie region in 2003-2006, which migrate northeast to southwest (Fig. 2). Figure 5 shows the tremor migration for four major episodes between 2004 and 2005. Although the details of each episode differ slightly, the tremor activity consistently initiates near the coast line of Ise Bay and migrates southwestward. In contrast, the tremor episode in January 2006 began in the southern edge of the Mie region and migrated northeast.

The spatiotemporal properties of the tremors in the Aichi region east of Ise Bay are more complex than for the Mie activity. Following elevated activity throughout 2003, major tremors began recurring at approximately 6 months intervals with major events in June 2004, December 2004, and July 2005. These episodes occurred within a month of the major tremor episodes in the Mie region, although no continuity in the tremor migration patterns are recognizable between the Aichi and Mie episodes. The subsequent tremor episode in January 2006, on the other hand, can be clearly recognized to be continuous across the Ise Bay boundary between the Mie and Aichi regions.

\section{Slow-slip Events}

In the Mie and Aichi regions, the periodic tremor activity is usually accompanied by short-term slow-slip event (Hirose and Obara, 2006; Obara and Hirose, 2006) detected by 


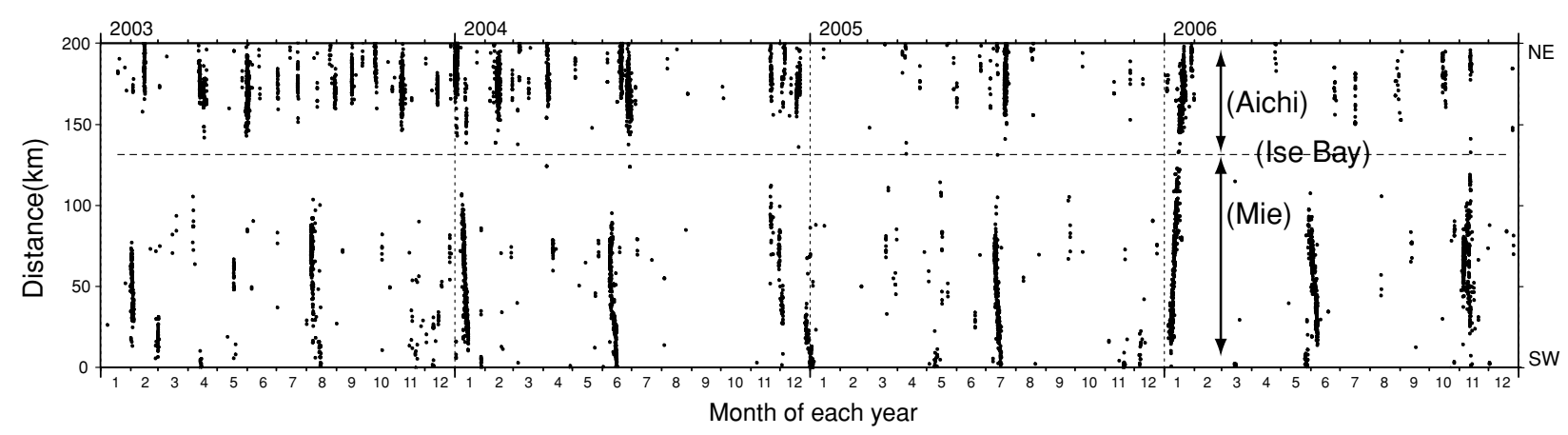

Fig. 2. Spatiotemporal distribution of tremors in Aichi and Mie regions from 2003 to 2006. Points denote well-located tremors (error of $<1$ km) as estimated by envelope cross-correlation at 2 min intervals.

(a)

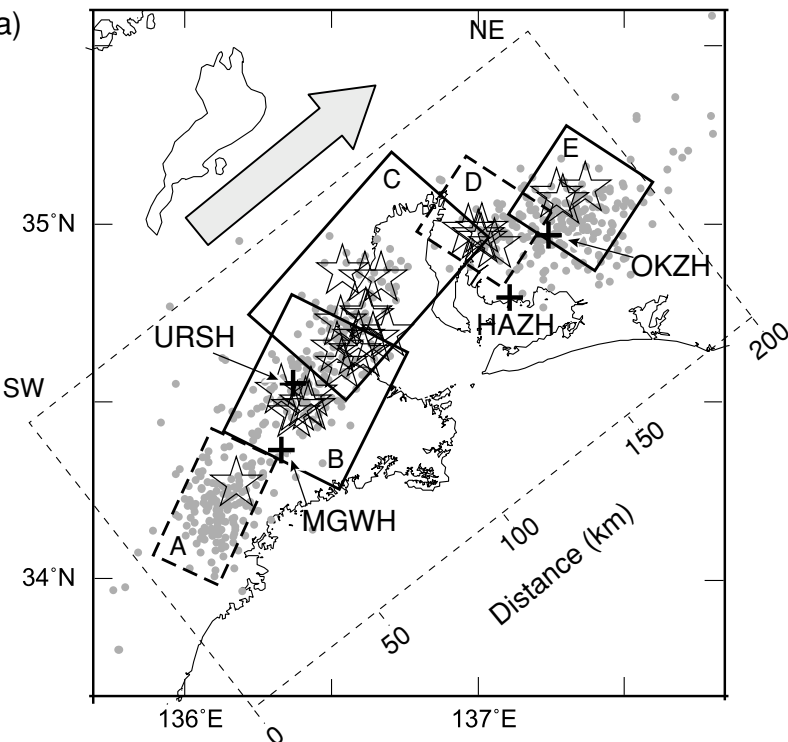

(b)

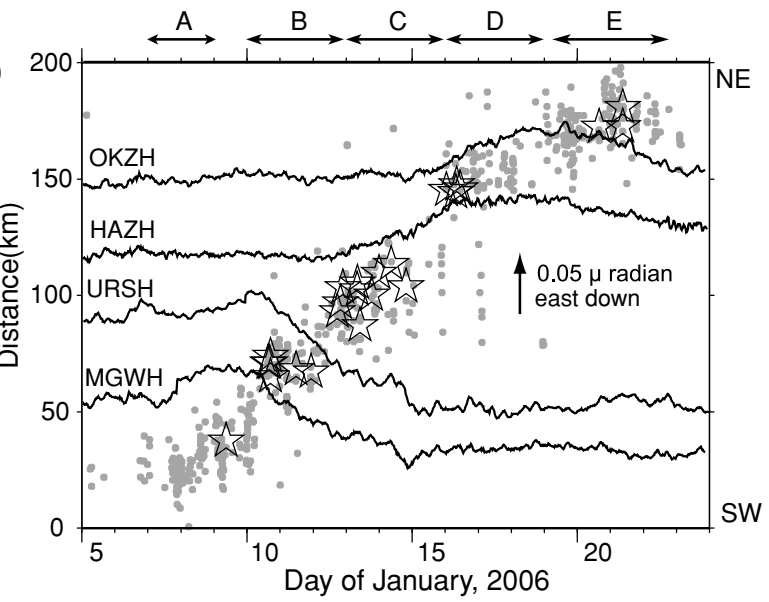

Fig. 3. (a) Epicentral distributions of low-frequency tremors (gray dots), VLF events (stars), and short-term slow-slip events in January 2006 for periods A-E. Crosses denote observation stations. (b) Spatiotemporal plot of low-frequency tremors, VLF events, and east-west tilt changes at each station.

high-sensitivity accelerometers (tiltmeters) installed at the base of boreholes at Hi-net stations (Obara et al., 2005). The major tremor episodes in the Mie region (January 2004, June 2004, November 2004, July 2005) and Aichi region (February 2004, June 2004, December 2004, and July
2005) were accompanied by slow-slip events. Such shortterm slow-slip events associated with major tremor episodes were previously undetected in the Aichi region, even though such events were known to occur in Shikoku and the Mie region (Obara and Hirose, 2006). The crustal deformation caused by such tremor-associated slow-slip events was first detected in real time in December 2004 using Hi-net tiltmeters (Hirose and Obara, 2006). Subsequent analysis of past strain-meter data by the Japan Meteorological Agency (JMA) revealed that every tremor peak is accompanied by a slow-slip event (Kobayashi et al., 2006).

Associated with the migrating tremor activity in January 2006, ground tilting was detected at many Hi-net stations by tiltmeters. Figure 3(b) shows examples of the time sequences of tilt movements observed at four stations along the tremor migration route. The tilt change continued at each station for a number of days, with the onset of the tilt change occurring later at each station following a northeastward propagation, indicating that the tilt change is closely associated with the tremor migration. The tilting episode can be divided into five periods based on the characteristic pattern of tilt change at each station and the spatiotemporal concentration of tremors and VLF events, as shown in Fig. 3(b). During the first period (period A, January 7-9), station MGWH in the Mie region recorded an east-down tilt change of $0.03 \mu \mathrm{rad}$, and tremors and a VLF event to the south. Stations MGWH and URSH then recorded simultaneous east-up tilting movements (period B, January 10-13), at which time tremors and VLF events were recorded in a concentrated region around station URSH. East-down tilting persisting for 4 days was later recorded at station $\mathrm{HAZH}$ on the eastern side of Ise Bay (period C, January 13-15), corresponding to a clustering of tremors and VLF events along the western side of Ise Bay. In the fourth period (period D, January15-18), station OKZH in the Aichi region recorded east-down tilting, and tremors and VLF events to the west. Finally, east-up tilting was observed at station $\mathrm{OKZH}$, and tremors and VLF events became concentrated around the station (period E, January 18-22). The geometry and slip parameters of each short-term slow-slip event were estimated from the tilt changes detected by Hi-net stations in the vicinity of each tremor source cluster during each of these periods. The tilt data (Fig. 6, left) were corrected for the Earth tide using Baytap-G (Tamura et al., 1991) and the linear trend of the drift. The north-south and east-west com- 

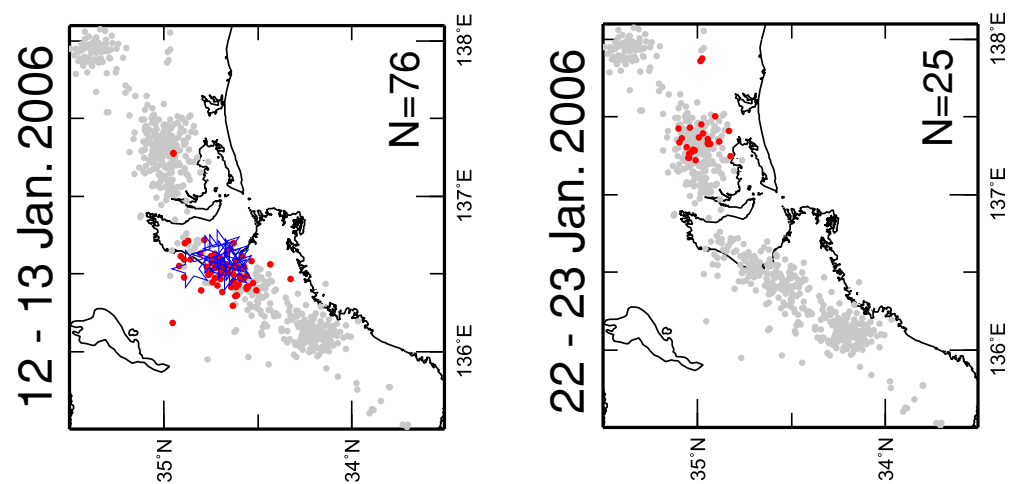

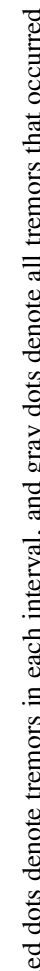
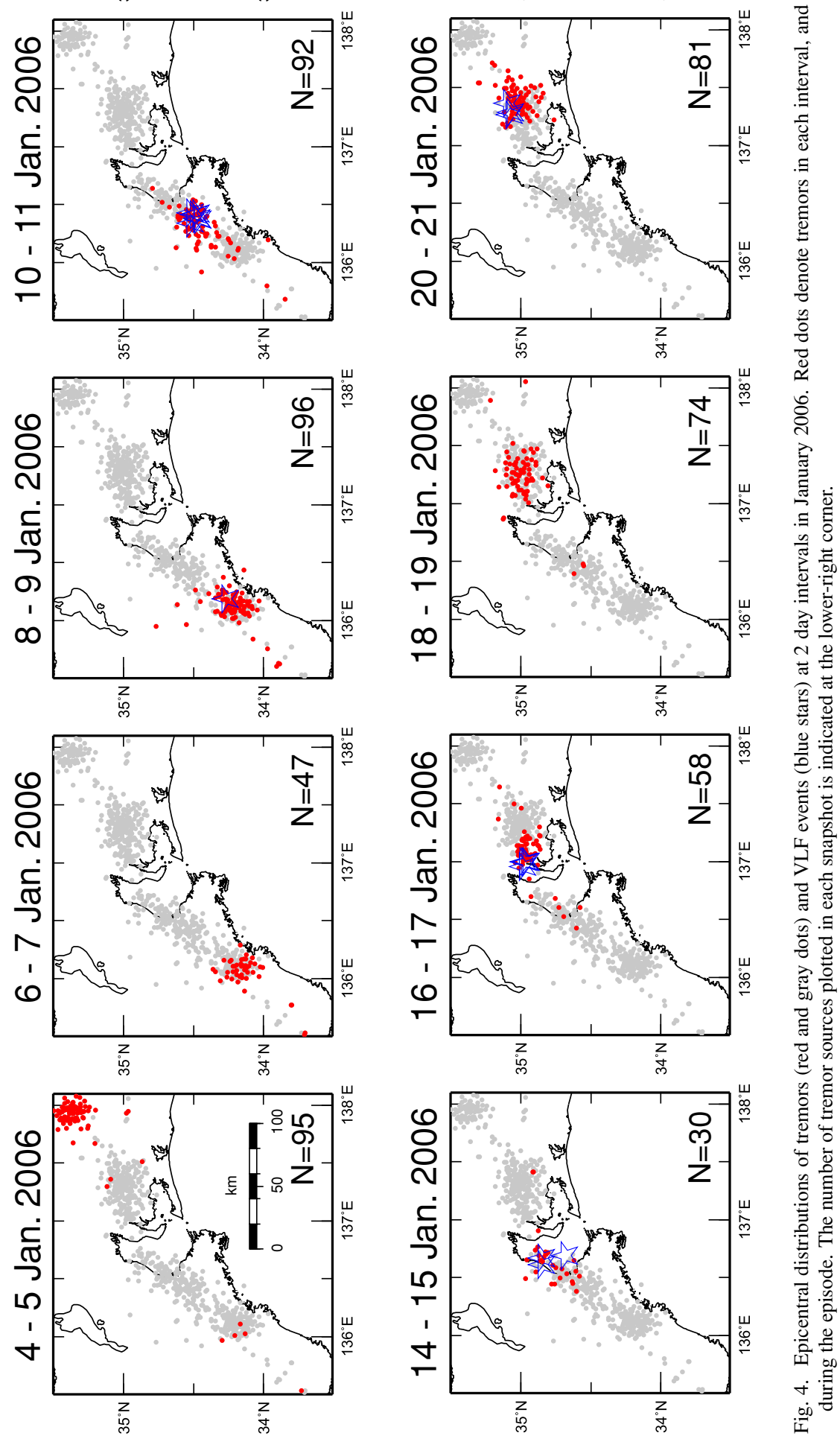

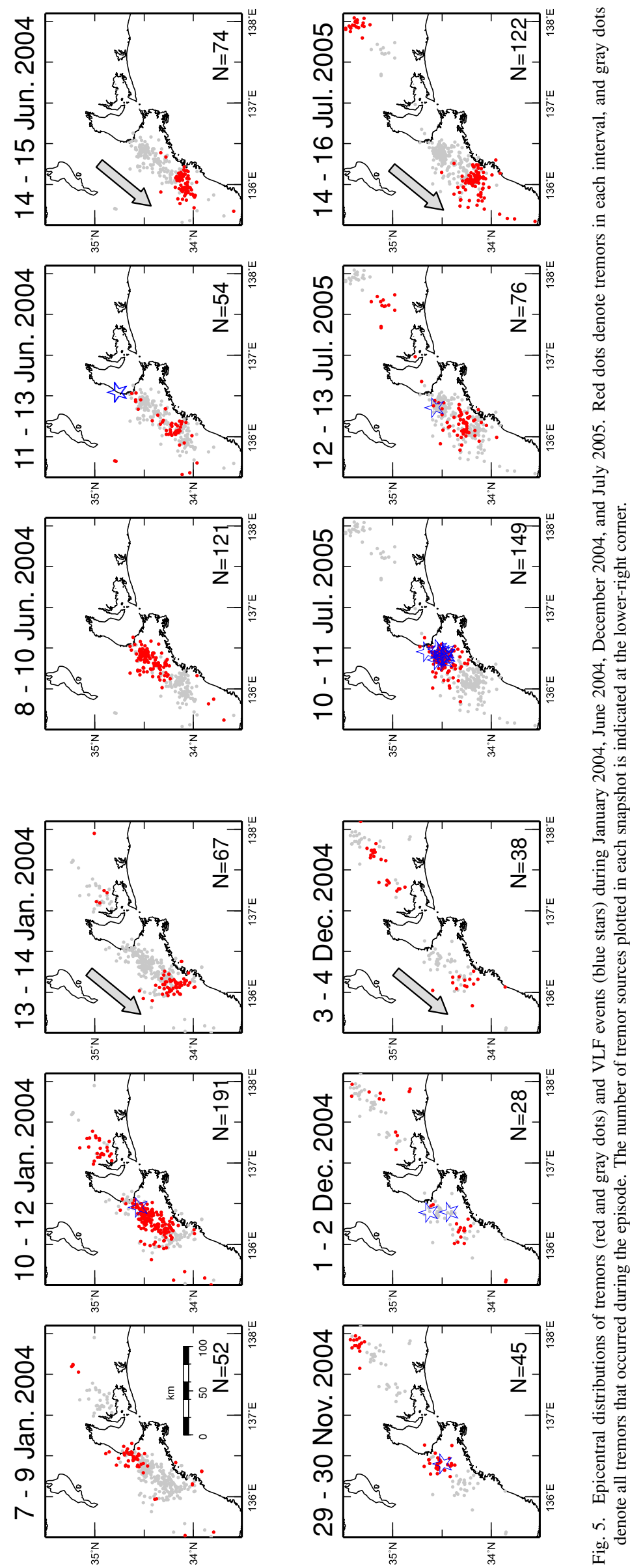

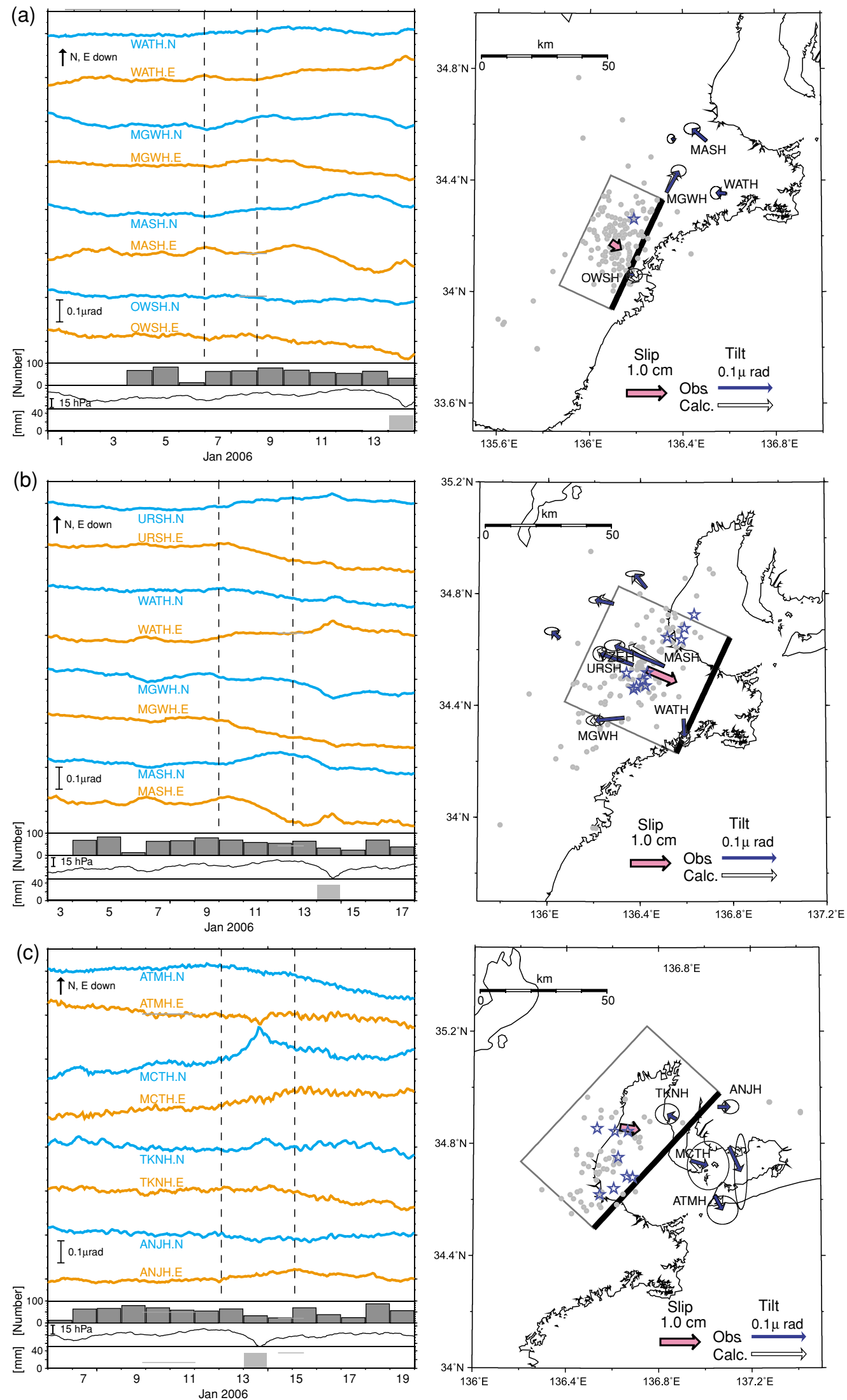

Fig. 6. Observed tilt data and estimated fault geometries for short-term slow-slip events. (Left) Tilt changes recorded at four stations over 14 days (linear trend removed). Blue and orange lines denote north-south and east-west component traces, and vertical dashed lines delineate the periods of tilt change. Histograms show tremor activity in the Mie and Aichi regions, and the graphs below show atmospheric pressure and precipitation. (Right) Estimated fault geometry at each station plotted against the observed and calculated tilt vectors. Gray dots denote low-frequency tremors, yellow stars denote VLF events, pink arrows denote slip vectors on the fault plane, boxes indicate estimated fault geometry, and bold lines denote the shallowest edge of the fault model. (a)-(e) Slow-slip events in periods A-E. 
(d)

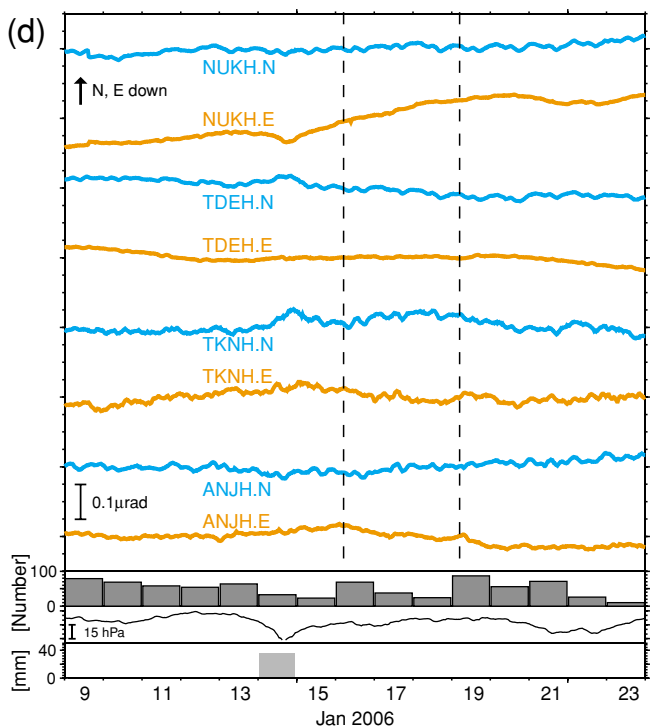

(e)

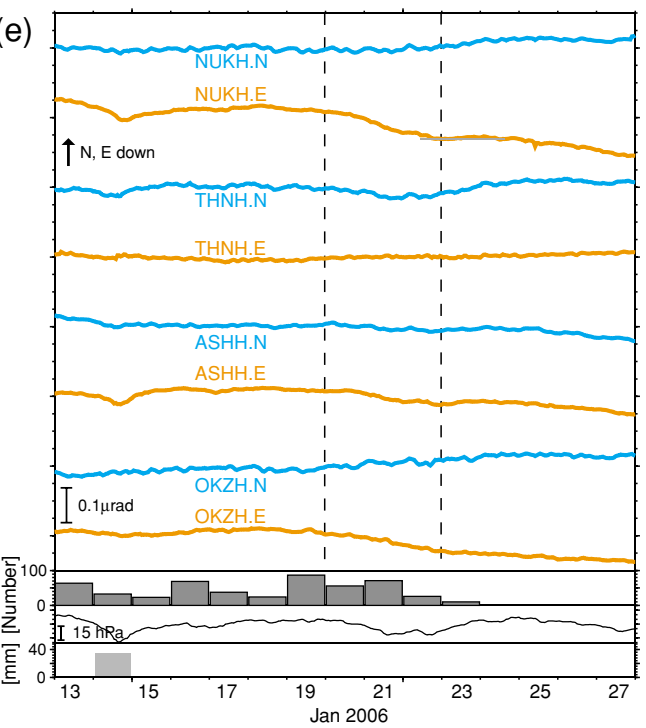

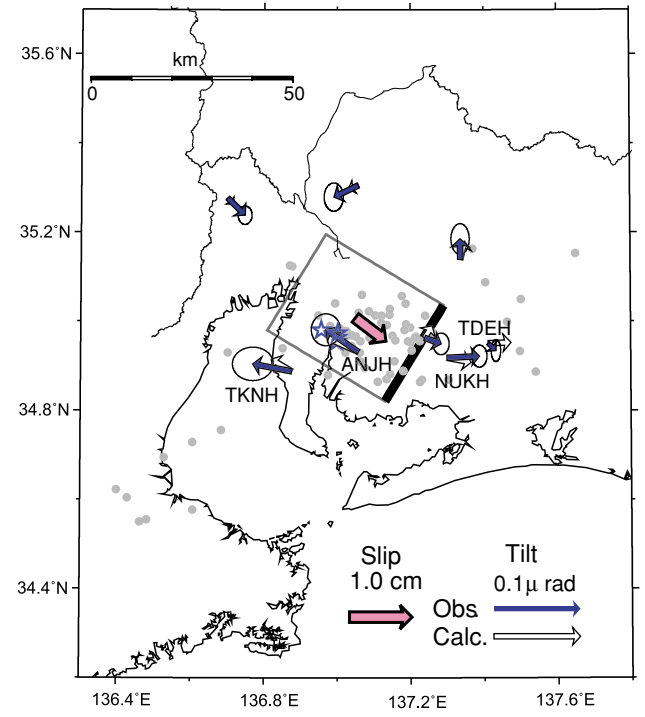

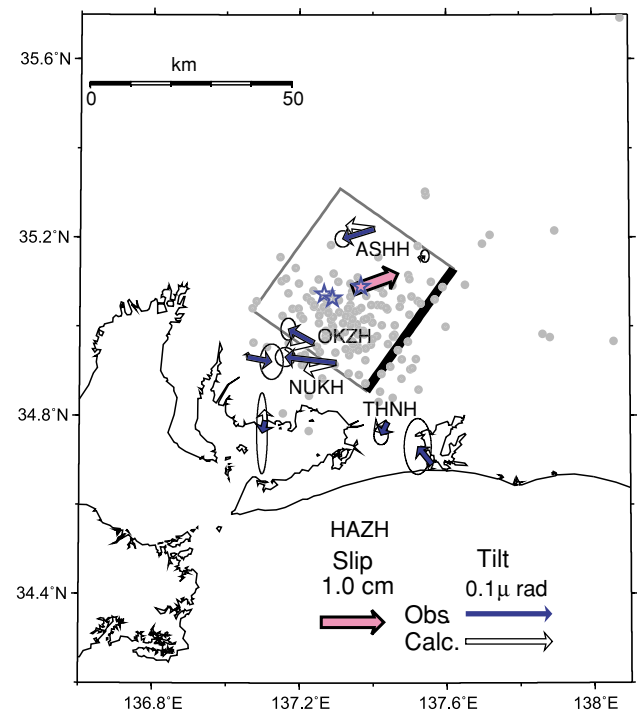

Fig. 6. (continued).

ponent tilt vectors obtained from the difference between the periods before and after the tilting event (Fig. 6, dashed lines) were then used to estimate the fault geometries and slip parameters for the five time periods (Fig. 3(b)) using a least-squares method given by Okada's formula (1992) and a genetic algorithm for optimization of the fault geometry (Obara et al., 2004; Hirose and Obara, 2005). The estimated fault geometries and slip parameters for each slowslip event are shown in Fig. 6 (right) and listed in Table 1. The slip direction for the first and fourth slow-slip events are fixed in the inversion process in consideration of the plate motion due to the lack of an approximately complete dataset. All slow-slip events are reverse fault type event occurring on the subducting plate boundary. The slip length of each slow-slip event ranges of $0.5-1.0 \mathrm{~cm}$, and the total moment release is equivalent to $M_{\mathrm{w}} 6.2$.

In the analysis above, the fault parameters for the five slow-slip events are estimated independently. However, as the resultant fault locations of the slow-slip events appear to be aligned along the strike of the subducting plate and belt-like tremor activity, and the tremor migration occurs at relatively uniform, the five events estimated above may constitute a single slow-slip event that propagates smoothly along strike. To examine this, a forward modeling of the evolution of the slow-slip event was attempted based on the migration of tremors and the pre-known plate geometry because an inversion analysis could not be performed due to insufficient tilt data. A fixed-size rectangle fault extending for $40 \mathrm{~km}$ along strike and $30 \mathrm{~km}$ down dip was assumed considering the distribution of tremors at each time point. The dip direction and depth were then fixed to coincide with the plate geometry (Shiomi et al., 2008), and the slow-slip event was set to migrate along the strike of the plate geometry at a propagation velocity of $10 \mathrm{~km} /$ day at the same depth and with a fixed slip rate of $0.5 \mathrm{~cm} /$ day. The slip direction of each fault was inferred from the motion of the Amurian and Philippine Sea plates. The synthesized time sequence of tilt change at each station was then compared with the observed data. Figure 7 shows the modeled tilt change for a smoothly propagating slow-slip event moving along the 
Table 1. Estimated fault geometries and slip parameters for slow-slip events in January 2006.

\begin{tabular}{rccccccccccr}
\hline & $\begin{array}{c}\text { Lat* } \\
\left({ }^{\circ} \mathrm{N}\right)\end{array}$ & $\begin{array}{c}\text { Long* } \\
\left({ }^{\circ} \mathrm{E}\right)\end{array}$ & $\begin{array}{c}\text { Strike } \\
\left({ }^{\circ}\right)\end{array}$ & $\begin{array}{c}\text { Dip } \\
\left({ }^{\circ}\right)\end{array}$ & $\begin{array}{c}\text { Depth } \\
(\mathrm{km})\end{array}$ & $\begin{array}{c}\text { Slip } \\
(\mathrm{cm})\end{array}$ & $\begin{array}{c}\text { Length } \\
(\mathrm{km})\end{array}$ & $\begin{array}{c}\text { Width } \\
(\mathrm{km})\end{array}$ & $\begin{array}{c}M_{0} \\
(\mathrm{~N} \mathrm{~m})\end{array}$ & $\begin{array}{c}M_{\mathrm{w}} \\
\text { Rake } \\
\left({ }^{\circ}\right)\end{array}$ \\
\hline$* * \mathrm{~A}$ & 34.333 & 136.314 & 205 & 12 & 11 & 0.31 & 48 & 23 & $1.37 \mathrm{E}+17$ & 5.4 & 80 \\
$\mathrm{~B}$ & 34.645 & 136.787 & 205 & 26 & 21 & 0.80 & 51 & 49 & $7.92 \mathrm{E}+17$ & 5.9 & 92 \\
$\mathrm{C}$ & 34.985 & 137.062 & 222 & 7 & 25 & 0.49 & 73 & 39 & $5.66 \mathrm{E}+17$ & 5.8 & 124 \\
$* * \mathrm{D}$ & 35.037 & 137.29 & 211 & 10 & 25 & 0.62 & 28 & 34 & $2.37 \mathrm{E}+17$ & 5.5 & 84 \\
$\mathrm{E}$ & 35.131 & 137.619 & 215 & 14 & 30 & 0.75 & 37 & 35 & $3.90 \mathrm{E}+17$ & 5.7 & 145 \\
\hline
\end{tabular}

*Upper northeast corner for each rectangle.

**Fixed slip direction.

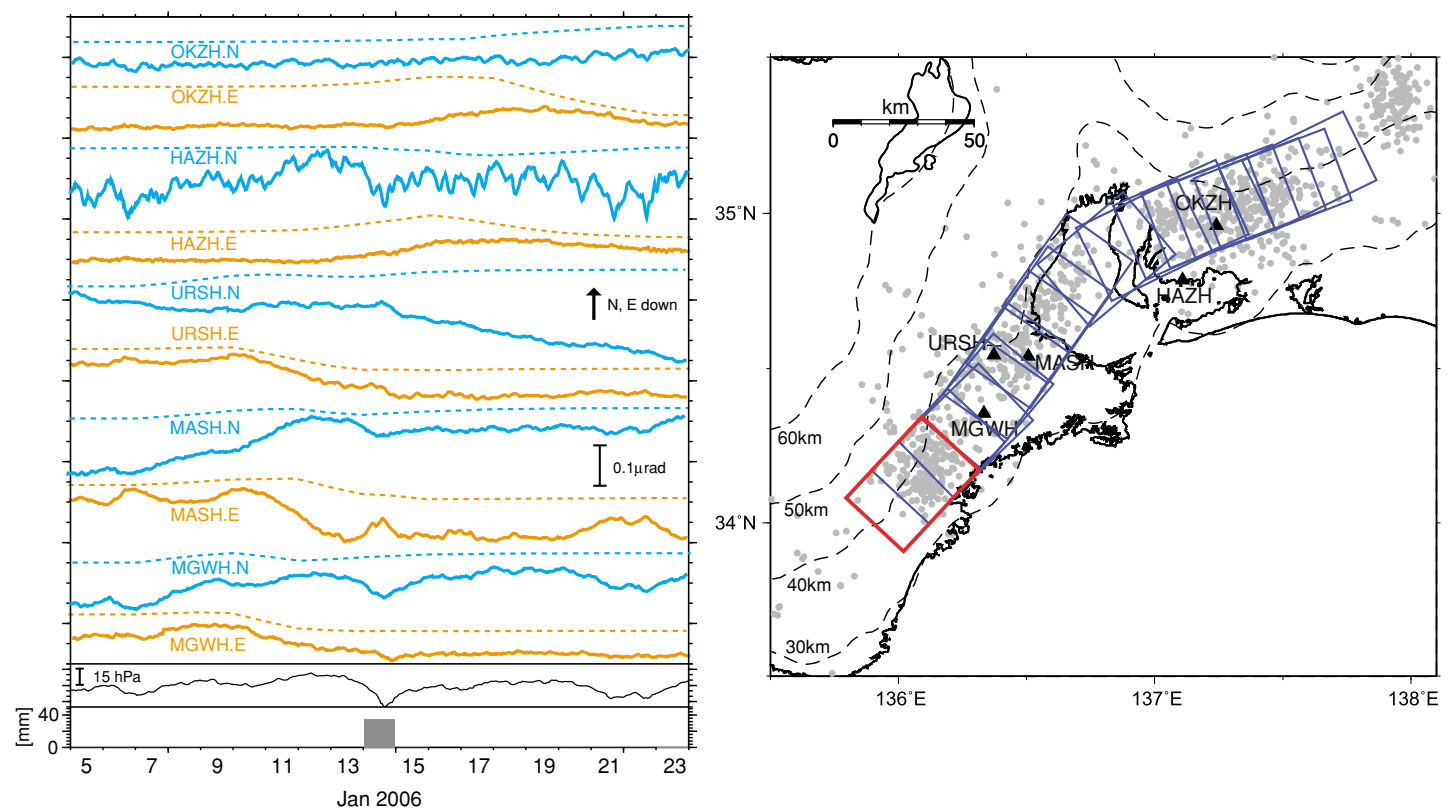

Fig. 7. Forward modeling of slow-slip event migrating continuously along the strike of the subducting Philippine Sea Plate. (Left) Observed (solid lines) and calculated (dashed lines) tilt changes in the period January 5-23. Blue and orange lines denote the north-south and east-west component traces, and graphs below show atmospheric pressure and precipitation. (Right) Geometry of migrating slow-slip fault. Red box denotes initial location, blue boxes denote daily snapshots of the migrating fault, gray dashed lines denote the depth contours of the oceanic Moho discontinuity in the subducting Philippine Sea Plate, and gray points denote the epicenters of low-frequency tremors.

plate boundary. The synthesized tilt trace is generally coincident with the observed data, although the traces diverge somewhat in the Aichi region suggesting that the model geometry or slip parameters employed in the model are not sufficiently representative in this region.

\section{Discussion}

The Mie and Aichi regions are active ETS segments in the belt-like tremor zone that follows the strike of the subducting Philippine Sea Plate. The ETS events recur at intervals of approximately 6 months, similar to the recurrence interval for ETS events in western Shikoku (Obara et al., 2004; Obara and Hirose, 2006). The periodic activity can be simply understood as a stick-slip process, characterized by periods of strain accumulation (ca. 6 months) culminating in slippage over a duration of several days. Yoshida and Kato (2003) obtained such periodic aseismic slip by numerical simulation using a two-degree-of-freedom blockspring model. However, it is difficult to reproduce the observed properties of the ETS activity. Tomography analysis suggests a high Poisson ratio in the tremor source region and the existence of high-pressure pore fluid (Shelly et al.,
2006; Matsubara et al., 2008). Fluid is stably generated by dehydration of the subducting oceanic plate under certain pressure and temperature conditions, and this liberated fluid may be responsible for the seismic velocity anomaly with high Poisson ratio. The recurrence interval of ETS events is controlled by the rate of strain accumulation and frictional properties, including the fluid condition and source size. Given the similarity between the recurrence intervals in the Mie and Aichi regions and in western Shikoku, the frictional properties and source sizes in these regions are likely to be very similar. In contrast, the recurrence intervals of ETS events in eastern and central Shikoku are considerably shorter (Obara and Hirose, 2006). Clarification of the relationships among recurrence interval, patch size, and the detailed pattern of slow-slip events will be helpful in constructing a friction law for stick-slip slow-slip event. In the northern Cascadia, for example, the recurrence interval of ETS events is 14-16 months, which may reflect a difference in the tectonic setting of the subduction zone.

The migration of the source of the slow-slip event in January 2006 was found to be coincident with that of the tremor episode, suggesting that the tremor activity may represent 
the rupture front of the slow-slip event. The rupture of the slow-slip event in this case is inferred to propagate horizontally, causing a migrating tremor. The extension and direction of the propagating rupture differ in each episode, as in western Shikoku (Obara and Hirose, 2006). In the Mie region, the tremor activity in the most cases migrated from northeast to southwest. However, the episode in January 2006 initiated at the southern edge of the Mie region and developed into the longest rupture event recorded to date in southwest Japan. The location of rupture initiation and the extent of the rupture zone may be controlled by small fluctuations in strain accumulation or fluid content in the patch of the slow-slip event, while the propagation direction of the ETS event may be determined by the configuration of the plate boundary.

Recent receiver function analyses have indicated that the plate geometry has curvature and shallows beneath Ise Bay (Shiomi et al., 2008), describing a small ridge structure. The present results then suggest that the pattern of tremors and slow-slip events is strongly affected by the existence of such a ridge, acting as a barrier to the propagation of the slow-slip event to produce a tremor seismicity gap. Regular ETS events occur independently on either side of the ridge at intervals of approximately 6 months. In the Mie region, the initiation of the ETS event is generally determined by the plate geometry, which causes the rupture to propagate to the south. However, during the episode in January 2006, the rupture initiated at the southern edge of the Mie region and propagated northeastward for the ridge. Such rupture propagating with a long distance might enhance the potential to cross the obstruction at Ise Bay, and continuing into the Aichi region. The tremor activity dropped in the vicinity of Ise Bay due to the geometric anomaly, and increased again upon propagation into the Aichi region as usual tremor activity.

Tremor episodes observed before January 2006 occurred on either side of Ise Bay within the space of a month, but without evidence for continuity between the two regions. If the size and frictional properties of both regions are similar, and both regions are subject to the same convergence rate regime, the recurrence intervals should be similar and the tremor activity can be expected to occur contemporaneously on some occasions. However, the January 2006 episode demonstrates a connection between the Mie and Aichi regions that allows continuous ETS migration. The synchronization of activity between these regions may therefore be due to the continuous propagation of a slow-slip event without occurrence of tremor, or some types of stress transfer between these regions. Another possible idea is that the potential of the occurrence of ETS in these regions is enhanced simultaneously by external source. The mechanism of such a rupture connection between segments of the slowslip event is similar to that for asperities associated with mega-thrust earthquakes, and may therefore provide useful information on the connection of ruptures in major earthquakes occurring just above the transition zone.

\section{Conclusion}

Episodic tremors and slow-slip events have been found in recent years to recur at intervals of approximately 6 months in the Mie and Aichi regions on either side of Ise Bay in central Japan. Tremor events in these two regions generally occur independently, yet within the space of one month, and are separated by a distinct tremor seismicity gap in the vicinity of Ise Bay. However, one episode of tremor and slow-slip event, recorded in January 2006, initiated uncharacteristically from the southern part of the Mie region and propagated northeastward, crossing Ise Bay, and migrating continuously into the Aichi region for a distance of approximately $200 \mathrm{~km}$ along the strike of the subducting Philippine Sea Plate. This is the longest propagation distance recorded for such events since monitoring of tremors in southwest Japan began in 2001. This tremor seismicity gap at Ise Bay is attributed to a small ridge in the Philippine Sea Plate that blocks northwest-southeast propagation of slow slip. The January 2006 event, however, migrated orthogonal to the prevailing migration direction and passed continuously through the ridge without impediment.

Acknowledgments. The authors extend their gratitude to Hitoshi Hirose for development of the inversion method for estimating slow slip events and to the staff of NIED for valuable assistance. Comments of two anonymous reviewers were very useful to improve the manuscript. We thank the reviewers for careful reading and thoughtful reviews. Maps were prepared using Generic Mapping Tools (Wessel and Smith, 1998). This research was carried out as a part of the NIED project entitled "Research Project for Crustal Activity based on Seismic Data".

\section{References}

Ando, M., Source mechanisms and tectonic significance of historical earthquakes along the Nankai trough, Japan, Tectonophys., 27, 119-140, 1975.

Dragert, H., K. Wang, and T. S. James, A silent slip event on the deeper Cascadia subduction interface, Science, 292, 1525-1528, 2001.

Dragert, H., K. Wang, and G. Rogers, Geodetic and seismic signatures of episodic tremor and slip in the northern Cascadia subduction zone, Earth Planets Space, 56, 1143-1150, 2004.

Hirose, H. and K. Obara, Repeating short- and long-term slow slip events with deep tremor activity around the Bungo channel region, southwest Japan, Earth Planets Space, 57, 961-972, 2005.

Hirose, H. and K. Obara, Short-term slow slip and correlated tremor episodes in the Tokai region, central Japan, Geophys. Res. Lett., 33, L17311, doi:10.1029/2006GL026579, 2006.

Hyndman, R. D., M. Yamano, and D. A. Oleskevich, The seismogenic zone of subduction thrust faults, Island Arc, 6, 244-260, 1997.

Ito, Y., K. Obara, K. Shiomi, S. Sekine, and H. Hirose, Slow earthquakes coincident with episodic tremors and slow slip events, Science, 315, 503-506, 2007.

Kobayashi, A., T. Yamamoto, K. Nakamura, and K. Kimura, Short-term slow slip events detected by the strainmeters in Tokai region in the period from 1984 to 2005, Zisin, 59, 2006 (in Japanese with English abstract).

Matsubara, M., K. Obara, and K. Kasahara, Three-dimensional $P$ - and $S$-wave velocity structures beneath the Japan Islands obtained by high-density seismic stations by seismic tomography, Tectonophys., doi:10.1016/j.tecto.2008.04.016, 2008.

Melbourne, T. I., W. M. Szeliga, M. M. Miller, and V. M. Santillan, Extent and duration of the 2003 Cascadia slow earthquake, Geophys. Res. Lett., 32, L04301, doi:10.1029/2004GL021790, 2005.

Miller, M. M., T. Melbourne, D. J. Johnson, and W. Q. Sumner, Periodic slow earthquakes from the Cascadia subduction zone, Science, 295, 2423, 2002.

Obara, K., Nonvolcanic deep tremor associated with subduction in southwest Japan, Science, 296, 1679-1681, 2002.

Obara, K. and H. Hirose, Non-volcanic deep low-frequency tremors accompanying slow slips in the southwest Japan subduction zone, Tectonophys., 417, 33-51, 2006.

Obara, K., H. Hirose, F. Yamamizu, and K. Kasahara, Episodic slow slip events accompanied by non-volcanic tremors in southwest 
Japan subduction zone, Geophys. Res. Lett., 31, L23602, doi:10. 1029/2004GL020848, 2004.

Obara, K., K. Kasahara, S. Hori, and Y. Okada, A densely distributed highsensitivity seismograph network in Japan: Hi-net by National Research Institute for Earth Science and Disaster Prevention, Rev. Sci. Instrum., 76, 021301, doi:10.1063/1.1854197, 2005.

Okada, Y., Internal deformation due to shear and tensile faults in a halfspace, Bull. Seismol. Soc. Am., 82, 1018-1040, 1992.

Okada, Y., K. Kasahara, S. Hori, K. Obara, S. Sekiguchi, H. Fujiwara, and A. Yamamoto, Recent progress of seismic observation networks in Japan-Hi-net, F-net, K-NET and KiK-net, Earth Planets Space, 56, xv-xxviii, 2004.

Rogers, G. and H. Dragert, Episodic tremor and slip on the Cascadia subduction zone: The chatter of silent slip, Science, 300, 1942-1943, 2003.

Sagiya, T. and W. Thatcher, Coseismic slip resolution along a plate boundary megathrust: The Nankai Trough, southwest Japan, J. Geophys. Res., 104, 1111-1129, 1999.

Shelly, D. R., G. C. Beroza, S. Ide, and S. Nakamula, Low-frequency earthquakes in Shikoku, Japan and their relationship to episodic tremor and slip, Nature, 442, 188-191, doi:10.1038/nature04931, 2006.

Shiomi, K., M. Matsubara, Y. Ito, and K. Obara, Simple relationship between seismic activity along Philippine Sea slab and geometry of oceanic Moho beneath southwest Japan, Geophys. J. Int., 173, 10181029, 2008.

Szeliga, W., T. I. Melbourne, M. M. Miller, and V. M. Santillan, Southern Cascadia episodic slow earthquakes, Geophys. Res. Lett., 31, L16602, doi:16610.11029/12004GL020824, 2004.

Tamura, Y., T. Sato, M. Ooe, and M. Ishiguro, A procedure for tidal analysis with a Bayesian information criterion, Geophys. J. Int., 104, 507-516, 1991.

Wessel, P. and W. H. F. Smith, New, improved version of Generic Mapping Tools released, EOS Trans. AGU, 79(47), 579, 1998.

Yoshida, S. and N. Kato, Episodic aseismic slip in a two-degree-offreedom block-spring model, Geophys. Res. Lett., 30, 1681, doi:10. 11029/2003GL017439, 2003.

K. Obara (e-mail: obara@bosai.go.jp) and S. Sekine 